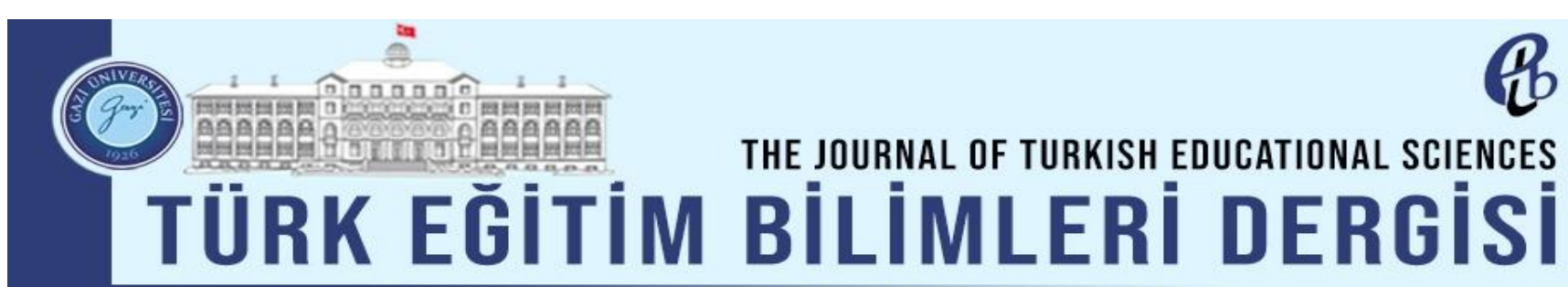

\title{
Üniversite Öğrencilerinde Pozitif-Negatif Duygu ve Mükemmeliyetçiliğin Yordayıcısı Olarak Öz Anlayış*
}

\section{Self Compassion as Predictor of Positive-Negative Affect and Perfectionism in University Students}

\begin{tabular}{|c|c|}
\hline \multicolumn{2}{|r|}{ Ersoy Çarkıt, Süleyman Barbaros Yalçın } \\
\hline Yazar Bilgileri & ÖZ \\
\hline $\begin{array}{l}\text { Ersoy CCarkıt } \\
\text { Arş. Gör., Nevşehir Hacı Bektaş } \\
\text { Veli Üniversitesi, Eğitim } \\
\text { Fakültesi, Rehberlik ve } \\
\text { Psikolojik Danışma } \\
\text { carkitersoy@nevsehir.edu.tr } \\
\text { Süleyman Barbaros Yalçın } \\
\text { Doç. Dr., Necmettin Erbakan } \\
\text { Üniversitesi, Rehberlik ve } \\
\text { Psikolojik Danışma } \\
\text { barbarosyalcin@konya.edu.tr }\end{array}$ & 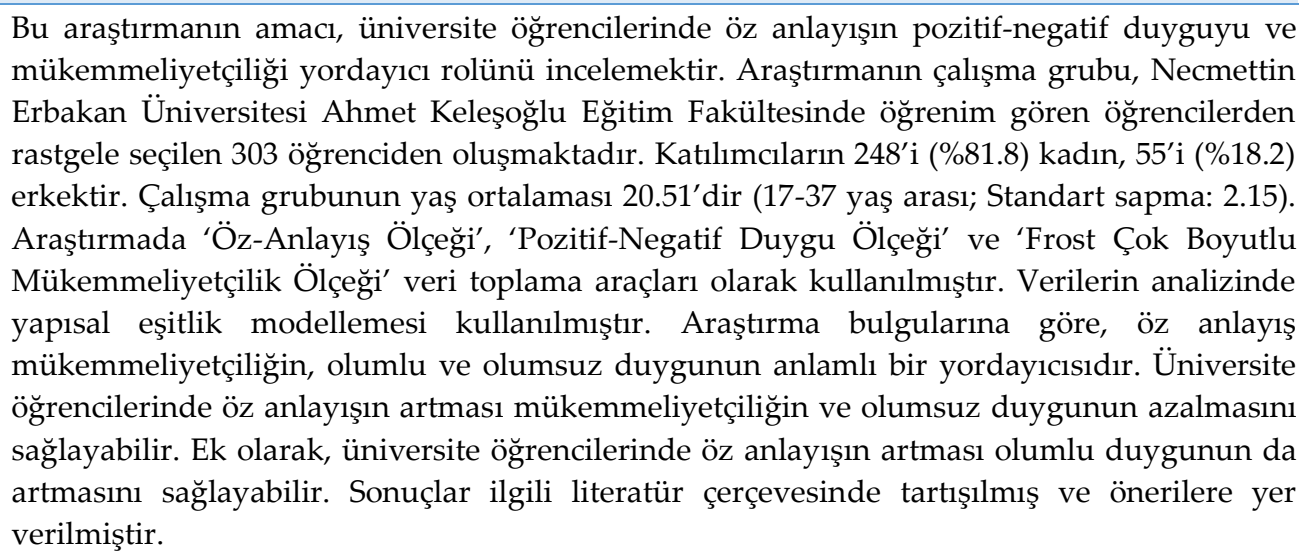 \\
\hline
\end{tabular}

\section{Makale Bilgileri}

Anahtar Kelimeler

Öz Anlayış

Mükemmeliyetçilik

Pozitif-Negatif Duygu

Keywords

Self Compassion

Perfectionism

Positive-Negative Affect

\section{Makale Geçmişi}

Geliş: 03.03.2020

Düzeltme: 19.01.2021

Kabul: 20.01.2021

\begin{abstract}
The aim of this study is to examine self-compassion as a predictor of positive-negative affect and perfectionism in university students. The relational survey method was administered in this study. The study group of the research consisted of 303 students ( 248 female / 55 male) who were randomly selected from Necmettin Erbakan University Ahmet Keleşoğlu Faculty of Education. The average age of the study group is 20.51 (from 17 to 37 years range; sd: 2.15). 'Self-Compassion Scale', 'Positive-Negative Affect Scale' and 'Frost Multidimensional Perfectionism Scale' were used in the study. As a result of the structural equation modeling, it is concluded that self-compassion is a significant predictor of positive-negative affect and perfectionism. The results showed that increasing self-compassion in university students might decrease their perfectionism and negative affect. In addition, increasing selfcompassion in university students can increase positive affect. The results are discussed in the literature.
\end{abstract}

*Bu çalışma, 18-21 Ekim 2017 tarihinde gerçekleştirilen II. Uluslararası Akademik Araştırmalar Kongresi'nde (INES) sözlü bildiri olarak sunulmuştur. 


\section{Giriş}

Belli durumlar karşısında verilen tepkilerde, bilişsel, duygusal ve güdüsel süreçlerde bireyler arası farklılıklar gözlenmektedir. Bu farklılıkların, kişilik özelliklerinden kaynaklandığı söylenebilir. Kişilik özellikleri bireylerin iyi oluşları ile yakından ilişkilidir (Butkovic, Brkovic ve Bratko, 2012; DeNeve ve Cooper, 1998). İnsanların iyi oluşları ile yakından ilişkili olduğu düşünülen mükemmeliyetçi kişilik özelliğinin ise günümüzde yaygınlığı artmıştır (Curran ve Hill, 2019). Çok boyutlu bir kişilik özelliği olan mükemmeliyetçilik (Frost, Marten, Lahart ve Rosenblate, 1990; Hewitt ve Flett, 1991), bireyin kendine katı standartlar belirlemesi, sorunlara neden olmasına rağmen bu standartların peşinden gitmesi ve bu süreçteki performansına dayanarak kendisini aşırı eleştirel bir tutumla değerlendirmesidir (Frost vd., 1990; Frost, Lahart ve Rosenblate, 1991; Shafran, Egan ve Wade, 2010). Mükemmeliyetçiliğin yaygın olarak araştırılan çok boyutlu modellerinden biri Frost vd.'nin (1990) altı boyutlu modelidir: Hata yapma endişesi, davranışlarından şüphe duyma, kişisel standartlar, yüksek ailesel eleştiri algısı, yüksek aile beklentileri algısı ve düzen. Mükemmeliyetçi bireyler, küçük hatalar yapmanın bile standartlarının karşılanmadığı algısı yaratmasından dolayı hata yapma endişesi yaşarlar. Davranışlarından şüphe duyma, mükemmeliyetçi bireylerin performans kaliteleri hakkındaki belirsizliğe işaret eder. Bir işin, tatmin edici bir şekilde, ne zaman tamamlandığ onlar için belirsizdir. Bunların yanı sıra mükemmeliyetçilerin kendi performanslarını değerlendirmeleri ebeveyn beklentileri ve onaylanma ya da onaylanmama varsayımına bağlıdır. Mükemmeliyetçi bireylerin sevgi ve onayın koşullu olduğu aile ortamında büyümesinden dolayı sevgi ve onay görebilmeleri için sürekli artan seviyelerde performans göstermeleri gerektiğine inanırlar. Mükemmeliyetçiler, ebeveynlerinin kendileri için karşılayamayacakları standartlar belirlediğini düşünür. Bu standartlara uyulmaması, ebeveyn kabulünün kaybı ve eleştirisi anlamına gelir. Mükemmeliyetçilerin diğer özelliği ise hassasiyet, düzen ve organizasyona aşırı vurgu yapmalarıdır. Düzen boyutu, standartların belirlenmesi ya da bu standartlara ilişkin performansın nasıl değerlendirildiği ile ilgili olmasa da, bireyin bu standartları karşılama görevini günlük olarak nasıl gerçekleştirdiği ilgilidir (Frost vd., 1990; Frost vd., 1991). Türkiye'de ve yurtdışında yapılan araştırmalarda mükemmeliyetçiliğin bilişsel hatalar ve mantıkdışı inançlarla (Çarkıt, 2016; Çarkıt ve Yalçın, 2018; Dilmaç, Aydoğan, Koruklu ve Deniz, 2009), yalnızlıkla (Arslan, Hamarta, Üre ve Özyeşil, 2010), bipolar bozuklukla (Fletcher vd., 2019) ve yoğun negatif duygularla (Castro, Soares, Pereira ve Macedo, 2017; Dunkley, Zuroff ve Blankstein, 2003; Kobori ve Tanno, 2005; Nejad, Besharat, Haddadi ve Abdolmanafi, 2011) pozitif yönde ilişkili olduğu bulunmuştur. Ayrıca mükemmeliyetçiliğin anksiyete ve depresif semptomları artırdığı (Arslan, Oral ve Karababa, 2018; Levine, Green-Demers, Werner ve Milyavskaya, 2019) ve yaşam doyumunu azalttığ (Karababa, 2018) bulunmuştur. Limburg, Watson, Hagger ve Egan (2017), mükemmeliyetçilik ve obsesif kompulsif bozukluk, kasten kendine 
zarar verme, anksiyete bozuklukları, intihar düşünceleri, depresyon, yoğun stres ve yeme bozuklukları gibi psikopatoloji arasındaki ilişkiyi meta analiz yöntemiyle incelemişlerdir. Çoğunluğu kadın ve yaş ortalaması yaklaşık 25 olan 57.200 katılımcıyı içeren 284 çalışma meta analiz kapsamına alınmıştır. Mükemmeliyetçilik ve psikopatoloji arasındaki ilişkide etki büyüklüğü 2.04 olarak hesaplanmıştır (Limburg vd., 2017). Bu araştırma bulgularından hareketle mükemmeliyetçiliğin psikolojik sağlık için bir risk faktörü olduğu söylenebilir. Buna karşın mükemmeliyetçiliğin yaratacağı olumsuz sonuçlar karşısında öz anlayışın koruyucu bir faktör olabileceği düşünülmektedir. Çünkü mükemmeliyetçi kişilik özelliğine sahip bireylerin aksine, kendisine karşı şefkatli olan bireyler, ağır öz yargılama ve öz eleştiri (Neff, 2003a, 2003b; Neff, Hsieh ve Dejitterat, 2005) yapmazlar. Bireylerin kendi kusurlarını kucaklayabilmesi, kendine karşı sevgi dolu, merhametli ve kibar olması mükemmeliyetçiliğin yıkıcı etkilerine karşı tampon görevi görebilir. Öz anlayışlı olmak bireyin kusurlu ve hatalı olduğu için kendini aşırı eleştirmeme eğilimidir (Pommier, Neff ve Tóth-Király, 2020). Bu özellik ise olumsuz mükemmeliyetçiliğe sahip bireylerde eksik olan bir özelliktir (Frost vd., 1990; James, Verplanken ve Rimes, 2015).

Öz anlayış, bireyin acı ve başarısızlık durumlarında öz eleştiri yapmak yerine kendine özenli ve merhametli davranmayı, negatif yaşam olaylarını yaşamın bir unsuru olarak görmeyi, olumsuz duygu ve düşüncelere aşırı odaklanmaktansa mantıklı bir bilinçle farkındalığa sahip olmayı ifade etmektedir (Neff, 2003a). Öz anlayış birbirine zıt olan üçü olumlu üçü olumsuz altı boyuttan oluşmaktadır. Öz şefkate karşı öz yargılama, bireyin kendisine sert, yargılayıcı ve eleştirel olmasından ziyade merhametli, şefkatli ve nazik bir tutum takınmasıdır. Paylaşımların bilincinde olmaya karşı yalıtım ise bireyin deneyimlediği bütün şanssızlık, sıkıntı ve acıları sadece kendisinin yaşadığına inanarak kendini diğer insanlardan ayrı görmek yerine yaşadığı bu olumsuzlukları birçok insanın da bunları deneyimleyebileceğini kabul etmesi demektir. Bilinçli farkındalığa karşı özdeşleşme, bireyin yaşadığı olumsuz olay ve acıları kendisiyle aşırı özdeşleştirmeden farkına varması, bunu yaparken olumsuz durumları yok saymadan ve abartmadan görmektir (Neff, 2003a, 2003b, 2009, 2012, 2016). Türkiye'de ve yurtdışında yapılan araştırmalarda öz anlayış bazı demografik değişkenlere göre incelenmiştir. Akyol (2011) ve Eker (2011) öz anlayışın algılanan sosyo-ekonomik düzeye göre farklılaşmadığını bulmuştur. Bacanlı ve Çarkıt (2020) ise yaptıkları meta analiz çalışmasında öz anlayışın cinsiyete göre anlamlı bir farklılık göstermediğini bulmuştur. Öz anlayış, üniversite öğrencilerinde depresyon ve kaygı ile negatif; iyi oluş, güvenli bağlanma ve sosyal bağlılıkla pozitif yönde ilişkili (Neff ve McGehee, 2010) bulunmuştur. Öz anlayış, kendini toparlama gücü (Kaygısız ve Traş, 2019; Sünbül ve Güneri, 2019), kişiler arası yapıcı problem çözme (Arslan, 2018), affedicilik (Oral ve Arslan, 2017; Wu, Chi, Zeng, Lin ve Du, 2019), sabır eğilimi (Eliüşük-Bülbül ve Arslan, 2017), insani değerler ve olumlu mizah tarzları (Baş ve Dilmaç, 2019; Dilmaç, Deniz ve Deniz, 2009) ve kayıp 
sonrası yas düzeyi ile pozitif yönde (Çağlar ve Taş, 2018) ilişkili bulunmuştur. Bu araştırmalar değerlendirildiğinde öz anlayışın bireylerde istendik özelliklerle yakından ilişkili olduğu görülmektedir. Buna karşın düşük düzeydeki öz anlayış ise depresyon, anksiyete, stres (Brophy, Brähler, Hinz, Schmidt ve Körner, 2020; Deniz ve Sümer, 2010), travmatik çocukluk yaşantıları (İme ve Taş, 2018) ve yüksek öfke (Arslan ve Adıgüzel, 2018) ile ilişkili olarak rapor edilmiştir. Bu araştırma bulgularına dayanarak öz anlayışın duygulanım süreçleriyle yakından ilişkili olduğu söylenebilir.

Duygusal eğilimin çok boyutlu ölçeklendirilme girişimlerinde ilk iki boyut olarak pozitif ve negatif dugulanım ortaya çıkmaktadır (Diener, Larsen, Levine ve Emmons, 1985; Watson, Clark ve Tellegen, 1984). Bu iki boyut, duygusal durumu temsil etse bile, olumlu ve olumsuz duygusal tepkilerde bireysel farklılığa işaret eden özelliklerle ilişkilidir (Tellegen, 1985). Tellegen (1985) pozitif ve negatif duyguyu, ödül ve ceza sinyallerine karşı psikobiyolojik ve psikodinamik duyarlılık yapılarına bağlamıştır. Ayrıca hem durum hem de özellik olarak pozitif ve negatif duygu, depresyon ve anksiyetenin başlıca ayırt edici özellikleridir (Tellegen, 1985). Yukarıda bahsedilen teorik açıklamalar ve araştırma bulgularına dayanarak, yüksek düzeyde öz anlayışın insanlarda hevesli, güçlü, ilhamlı, uyanık, ilgili, güçlü, kararlı olmak gibi pozitif duygular (Watson, Clark ve Tellegen, 1988) yaratacağı söylenebilir. Düşük düzeyde öz anlayışın insanlarda mutsuzluk, suçluluk, tedirginlik, asabiyet gibi negatif duygular (Watson vd., 1988) yaratacağı söylenebilir.

Önceki araştırmalara göre, son yıllarda gençlerde olumsuz mükemmeliyetçiliğin daha yaygın hâle geldiği rapor edilmektedir (Curran ve Hill, 2019). Gençlerde mükemmeliyetçiliğin yaygınlığı ve olumsuz sonuçları (bakınız; Arslan vd., 2018; Castro vd., 2017; Limburg vd., 2017) dikkate alındığında gerek mükemmeliyetçiliğin önlenmesi gerekse mükemmeliyetçiliğe müdahale edilerek öznel iyi oluşun sağlanmasında, mükemmeliyetçilikle ilişkili olan kavramların bilinmesi önemli görülmektedir. Ayrıca öznel iyi oluşun sağlanmasında pozitif duygunun fazla, negatif duygunun ise az olması gerekir (Diener, 1984; Myers ve Diener, 1995). Dolayısıyla pozitif-negatif duyguyla ilişkili kavramların da bilinmesi önemlidir. Bu nedenle bu çalışmada üniversite öğrencilerinde öz anlayışın pozitif-negatif duygu ve mükemmeliyetçilik özelliklerini yordayıcı rolünü incelemek amaçlanmıştır. Araştırma sonuçlarının eğitim ortamlarında ve ruh sağlığı hizmeti verilen kurumlarda mükemmeliyetçilik ile baş etmek, mükemmeliyetçiliğin yaygınlığını azaltmak ya da oluşumunu önlemek için geliştirilecek olan bireysel veya grupla müdahale hizmetleri için kılavuz olabileceği, araştırmacı ve uygulayıcılar için doğurguları olacağı düşünülmektedir. Bu araştırma sonuçlarının benzer şekilde bireylerde olumlu duygunun artırılması ve olumsuz duygunun azaltılması için planlanan müdahale çalışmalarına da rehberlik etmesi beklenmektedir. Ayrıca bu araştırma sonuçlarının gelecek çalışmalar için araştırmacılara fikir vereceği ve alandaki bilgi birikimine katkıda bulunacağı söylenebilir. 


\section{Yöntem}

İlişkisel tarama modeline göre yürütülmüş bu araştırmada üniversite öğrencilerinin pozitifnegatif duyguları, mükemmeliyetçilikleri ve öz anlayışları arasındaki ilişkiler incelenmiştir. İlişkisel tarama modeli, sadece durumları veya olayları betimlemenin ötesinde olası ilişkileri inceleyerek bir olguyu daha iyi anlamaya ve ön görülerde bulunmaya olanak sağlar (Büyüköztürk, Kılıç-Çakmak, Akgün, Karadeniz ve Demirel, 2008). Değişkenler arasındaki yordayıcı ilişkiler Yapısal Eşitlik Modellemesi ile incelenmiştir.

\section{Çalışma Grubu}

Araştırmanın çalışma grubu, Necmettin Erbakan Üniversitesi Ahmet Keleşoğlu Eğitim Fakültesinden seçkisiz olarak belirlenen ve çalışmaya katılma konusunda gönüllü olan 303 (248 kadın - \%81.8; 55 erkek - \%18.2) üniversite öğrencisinden oluşmaktadır. Çalışma grubunun yaş ortalaması 20.51 'dir $\left(S_{s}=2.15 ; 17-37\right.$ yaş arası).

\section{Veri Toplama Araçları}

\section{Öz Anlayış Ölçeği (ÖZAN):}

Orijinali Neff (2003b) tarafından geliştirilen Öz Anlayış Ölçeği, 6 alt ölçek ve 26 maddeden oluşmaktadır. Bu ölçek 5'li likert tipindedir (1: Hemen hemen hiçbir zaman; 5: Hemen hemen her zaman). ÖZAN'ın Türk üniversite öğrencilerine uyarlama çalışmasını Deniz, Kesici ve Sümer (2008) yapmıştır. Orijinalinden farklı olarak Türkçe ÖZAN, tek boyutlu bir yapıda iyi uyum göstermiştir. Ayrıca orijinalinde olan iki madde, madde toplam korelasyonunun düşük olmasından dolayı Türkçe formundan çıkarılmıştır. Türkçe ÖZAN, 24 madde ve tek boyuttan oluşmaktadır. Türkçe ÖZAN'ın iç tutarlılık katsayısı .89; test-tekrar test korelasyon .83 olarak bulunmuştur. ÖZAN'ın ölçüt bağıntılı geçerlik çalışması için birlikte uygulanan ölçeklerle korelasyon katsıyısıları ise orta ve yüksek düzeydedir (Deniz vd., 2008). Bu araştırmada Cronbach Alfa değeri .92 olarak bulunmuştur.

\section{Pozitif-Negatif Duygu Ölçeği (PANAS):}

Orijinali Watson vd. (1988) tarafından geliştirilen Pozitif-Negatif Duygu Ölçeği, olumlu ve olumsuz duygulanımı ölçen 10'ar maddelik iki alt ölçekten oluşmaktadır. Ölçek 5'li liker tipindedir (1: Çok az veya hiç; 5: Çok fazla). Pozitif-Negatif Duygu Ölçeği'nin Türkçe uyarlama çalışması Gençöz (2000) tarafından yapılmıştır. Türkçe Pozitif-Negatif Duygu Ölçeği'nin iç tutarlılık katsayısı pozitif duygu alt boyutu için .83, negatif duygu alt boyutu için .86 olarak bulunmuştur. Türkçe PozitifNegatif Duygu Ölçeği'nin kararlılık katsayısı ise pozitif duygu alt boyutu için .40, negatif duygu alt boyutu için .54 olarak bulunmuştur. Türkçe Pozitif-Negatif Duygu Ölçeği'nin ölçüt bağıntılı geçerliği için birlikte uygulandığı ölçeklerle ilişki katsayısı ise orta ve düşük düzeydedir (Gençöz, 2000). Türkçe 
Pozitif-Negatif Duygu Ölçeği'nin iç tutarlılık katsayısı bu araştırmada pozitif duygu alt boyutu için .85 , negatif duygu alt boyutu için .83 olarak bulunmuştur.

\section{Frost Çok Boyutlu Mükemmeliyetçilik Ölçeği (FÇBMÖ):}

Orijinalini Frost vd.'nin (1990) geliştirdiği FÇBMÖ, 35 madde ve 6 alt ölçekten oluşmaktadır. FÇBMÖ 5'li likert tarzındadır. FÇBMÖ'nün alt ölçekleri, hatalara karşı duyarlılık, yüksek standartlar, ailesel eleştiri, davranışlarından şüphe duyma, aile beklentileri ve düzendir. FÇBMÖ'nün Türkçe uyarlama çalışması Kağan (2011) tarafından yapılmıştır. Türkçe FÇBMÖ, orijinalinde olduğu gibi 35 madde ve 6 alt ölçekten oluşmaktadır. Ölçeğin doğrulayıcı faktör analizi sonucunda iyi uyum gösterdiği bulunmuştur $(\chi 2 / \mathrm{sd}=2.48, \mathrm{RMSEA}=0.06 ; \mathrm{CFI}=0.96$ ve SRMS=0.07). Türkçe FÇBMÖ'nün iç tutarlılık katsayısı .64 ile .94 aralığında değişmektedir (Kağan, 2011). Bu araştırmada Türkçe FÇBMÖ'nün iç tutarlılık katsayısı hata yapma endişesi için .80, yüksek kişisel standartlar için .72, aile beklentileri için .81, ailesel eleştiri için .71 yaptığından emin olamama için .68 ve düzen için .95 olarak bulunmuştur.

\section{Kişisel Bilgi Formu:}

Katılımcıların yaş ve cinsiyet bilgilerine ilişkin soruları içeren ve araştırmacılar tarafından oluşturulan formdur.

İşlem

Üniversite öğrencilerinin pozitif-negatif duygulanım ve mükemmeliyetçiliklerinde öz anlayışın yordayıcı rolünü incelemek için yapısal eşitlik modellemesinden yararlanılmıştır. Veriler SPSS 26 ve AMOS 24 paket programları kullanılarak analiz edilmiştir.

Tablo 1: Tanılayıcı İstatistik, Cronbach Alfa Değeri ve Değişkenler Arası İlişki

\begin{tabular}{|c|c|c|c|c|c|c|c|c|c|}
\hline Değişkenler & 1 & 2 & 3 & 4 & 5 & 6 & 7 & 8 & 9 \\
\hline 1. Öz Anlayış & - & & & & & & & & \\
\hline 2. Pozitif Duygu & $.44^{* *}$ & - & & & & & & & \\
\hline 3. Negatif Duygu & $-.46^{* *}$ & $-.31^{* *}$ & - & & & & & & \\
\hline 4. Hata Yapma Endişesi & $-.54^{* *}$ & -.10 & $.34^{* *}$ & - & & & & & \\
\hline 5. Kişisel Standartlar & -.04 & $.33^{* *}$ & .04 & $.46^{* *}$ & - & & & & \\
\hline 6. Aile Beklentileri & -.08 & $.16^{* *}$ & $.17^{* *}$ & $.40^{* *}$ & $.43^{* *}$ & - & & & \\
\hline 7. Ailesel Eleştiri & $-.26^{* *}$ & -.08 & $.26^{* *}$ & $.47^{* *}$ & $.21^{* *}$ & $.49^{* *}$ & - & & \\
\hline 8. Davranışlarından Şüphe & $-.44^{* *}$ & -.07 & $.30^{* *}$ & $.61^{* *}$ & $.28^{* *}$ & $.34^{* *}$ & $.40^{* *}$ & - & \\
\hline 9. Düzen & $.17^{* *}$ & $.29^{* *}$ & -.11 & -.05 & $.29^{* *}$ & .03 & -.11 & 0.05 & - \\
\hline$x$ & 78.45 & 32.87 & 21.26 & 18.48 & 22.40 & 12.55 & 6.97 & 10 & 23 \\
\hline Ss & 16.15 & 7.92 & 7.42 & 5.95 & 5.19 & 4.86 & 3.05 & 3.14 & 5.72 \\
\hline$\alpha$ & .92 & .85 & .83 & .80 & .72 & .81 & .71 & .68 & .95 \\
\hline Çarpıklık & -.22 & -.36 & .83 & .63 & .10 & .35 & 1.16 & .18 & -.65 \\
\hline Basıklık & -.29 & -.43 & .11 & .24 & -.36 & -.56 & 1.03 & -.44 & -.15 \\
\hline
\end{tabular}

Değişkenlere ilişkin veriler uç değerler, normal dağılım ve çoklu doğrusallık bakımından test edilmiştir. Ön analiz sonuçları Tablo 1'de sunulmuştur. Ön analizler sonucunda (Tablo 1) gerekli 
varsayımların sağlandığı görülmüştür. Maksimum olabilirlik (Maximum likelihood) istatistiği kullanılarak test edilen model için uyum iyiliği değerleri, Hu ve Bentler'in $(1998,1999)$ önerdiği $(\chi 2 /$ sd $\leq 3 ;$ RMSEA $\leq .06 ;$ SRMR $\leq .08)$ sınırlar doğrultusunda değerlendirilmiştir. Araştırmada uç değerler $\mathrm{z}$ değerleri hesaplanarak araştırılmıştır. Bu değerlerin \pm 3.29 aralığında olmasından dolayı (Tabachnick ve Fidel, 2013) uç değerin olmadığı söylenebilir. Tablo 1 incelendiğinde değişkenler arasındaki ilişkilerin çoklu doğrusallığa neden olacak kadar yüksek olmadığı görülmektedir. Ayrıca değişkenlerin çarpıklık ve basıklık değerleri \pm 1.5 aralığında (Tabachnick ve Fidel, 2013) olduğu için verilerin normal dağılıma sahip olduğu söylenebilir.

\section{Bulgular}

Bu bölümde ön analiz ve yapısal eşitlik modellemesi bulgularına yer verilmiştir. Araştırmada test edilen model aşağıda verilmiştir.

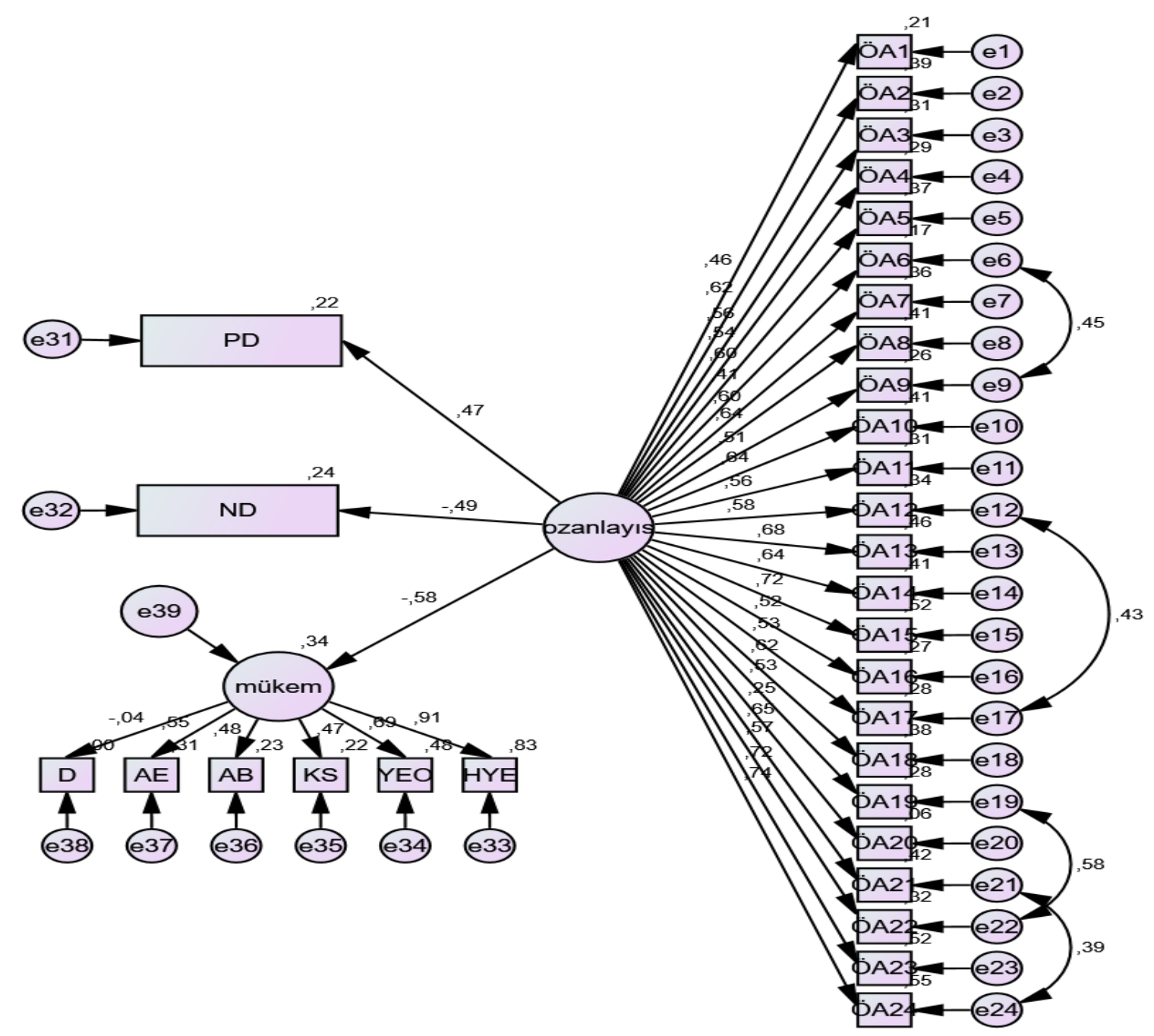

Şekil 1. Öz Anlayışın Mükemmeliyetçilik ve Duyguları Yordamasına İlişkin Test Edilen Model

Şekil 1 ve Tablo 2'de görüldüğ̈̈ gibi öz anlayış mükemmeliyetçiliğin $(\beta=-.582, p=0.000)$, pozitif duygunun $(\beta=.470, p=0.000)$ ve negatif duygunun $(\beta=-.485, p=0.000)$ anlamlı bir 
yordayıcısıdır. Öz anlayış mükemmeliyetçiliğe ilişkin toplam varyansın yaklaşık \%34'ünü $\left(R^{2}=.339\right.$, $p=0.000)$, pozitif duygunun $\% 22^{\prime} \operatorname{sini}\left(R^{2}=.220, p=0.000\right)$ ve negatif duyguya ilişkin varyansın ise yaklaşık \%24'ünü $\left(R^{2}=.236, p=0.000\right)$ açıklamaktadır.

Tablo 2. Üniversite Öğrencilerinde Pozitif-Negatif Duygu ve Mükemmeliyetçiliğin Yordayıcısı Olarak Öz Anlayışın Yol Katsayıları

\begin{tabular}{lclcccc}
\hline Yordayıcı & & Yordanan & $\boldsymbol{B}$ & S.H. & Beta & $\boldsymbol{t}$ \\
\hline Öz anlayış & $\rightarrow$ & Mükemmeliyetçilik & -3.700 & .425 & -.582 & -8.706 \\
\hline Öz anlayış & $\rightarrow$ & Pozitif Duygu & 4.364 & .552 & .470 & 7.902 \\
\hline Öz anlayış & $\rightarrow$ & Negatif Duygu & -4.228 & .515 & -.485 & -8.208 \\
\hline
\end{tabular}

Modele ilişkin uyum iyiliği değerlerinden $\chi 2=1107.124 ; p=0.000 ; d f=459 ; \chi 2 / d f=2.41$; $R M S E A=.06 ; S R M R=.07$ değerleri kabul edilir uyuma işaret etmektedir (Hu ve Bentler, 1998, 1999). Öz anlayış; hata yapma endişesini $(d=-.53)$, yaptığından emin olamamayı $(d=-.40)$, ailesel eleştiriyi $(d=-.32)$, aile beklentilerini $(d=-.28)$ ve kişisel standartları $(d=-.27)$ negatif yönde ve dolaylı olarak; düzeni $(d=.02)$ ise pozitif yönde ve dolaylı olarak etkilemektedir. Öz anlayış pozitif duyguyu $(d=.47)$ olumlu yönde, negatif duyguyu ( $d=-.48$ ) olumsuz yönde doğrudan etkilemektedir. Cohen'e (1992) göre korelasyon temelli etki büyüklüklerinin yorumlanmasında .10 düşük, .30 orta, .50 ve üzeri güçlü olarak yorumlanmaktadır.

\section{Tartışma, Sonuç ve Öneriler}

$\mathrm{Bu}$ araştırmada üniversite öğrencilerinde öz anlayışın pozitif-negatif duygu ve mükemmeliyetçilik özelliklerini yordayıcı rolünü incelemek amaçlanmıştır. Araştırma bulguları öz anlayışın mükemmeliyetçilik, pozitif ve negatif duygu için önemli bir yordayıcı olduğunu göstermiştir.

Araştırma bulgularına göre üniversite öğrencilerinde öz anlayış, pozitif duyguyu olumlu ve negatif duyguyu olumsuz yönde anlamlı şekilde yordamaktadır. Bu bulgudan hareketle üniversite öğrencilerinin, olumsuz durumlar karşısında öz yargılama olmadan kendilerine özenli olmalarının, olumsuzlukları hayatın bir parçası olarak görmelerinin, bilinçli farkındalığa sahip olmalarının sevinç, mutluluk, coşku, heyecan, gurur, güven gibi olumlu duyguları arttıracağı; kaygı, üzüntü, korku, incinmişlik, kızgınlık gibi olumsuz duyguları azalacağı söylenebilir. Birçok çalışmada öz anlayışın; pozitif duygu, yaşam doyumu, umut, iyi oluş, mutluluk, iyimserlik gibi olumlu durumları güçlendirdiği ve bu durumlarla pozitif yönde ilişkili olduğu bulurken; öz anlayışın negatif duygu, anksiyete, depresyon, stres gibi olumsuz durumları azalttığı ve bu durumlarla ters yönde ilişkili olduğu bulunmuştur (Deniz, Arslan, Özyeşil ve İzmirli, 2012; Deniz vd., 2008; Deniz ve Sümer, 2010; Kriger, Hermann, Zimmermann ve Holtforth, 2015; Leary, Tate, Adams, Allen ve Hancock, 2007; Neff, 2003b; Neff, Rude ve Kirkpatrick, 2007; Neff ve Vonk, 2009; Öveç, 2007; Trompetter, de Kleine ve Bohlmeijer, 2017; Yang, Zhang ve Kou, 2016). Araştırma bulguları ile paralel olarak Neff (2003b) Öz 
Anlayış Ölçeği'ni geliştirme çalışmasında öz anlayışın, öz-eleştiri ile negatif yönde, sosyal bağlantı ile pozitif yönde ilişkili olduğunu rapor etmiştir. Buna ilaveten psikolojik sağlık için öz anlayışın önemli bir yordayıcı olduğu rapor edilmiştir. Deniz vd. (2012), üniversite öğrencileri üzerinde yaptıkları çalışmada öz anlayışı, pozitif duygu ve yaşam memnuniyeti ile olumlu, negatif duygu ile olumsuz yönde anlamlı bir ilişki tespit etmişlerdir. Leary vd. (2007), yüksek öz anlayış düzeyine sahip bireylerin yaşadıkları istenmeyen yaşam olaylarını anlatırken daha az negatif duygu gösterdikleri ve çevreden soyutlanmadan bu durumların üstesinden geldiklerini bildirmişlerdir. Neff ve Lamb (2009), öz anlayış; özellikle iyi oluş ve sağlığın çekirdek yapılarıyla ilgilidir. Öz anlayış, kaygı ve depresyonu azaltırken mutluluğu ve benlik saygısını geliştiren duygu düzenleme stratejisidir (Neff, 2003b; Neff vd., 2007). Bunu da negatif duygu ve düşünceleri öz kabule dönüştürerek yapmaktadır (Gilbert ve Procter, 2006; Neff, Kirkpatrick ve Rude, 2006). Öz anlayışla ilgili değişkenler dikkate alındığında; öz anlayış düzeyi yüksek olan bireylerin daha çok pozitif duygular yaşarken negatif duyguları daha az yaşadığı, yaşamdan daha çok doyum elde ettiği; anksiyete, stres ve depresyonlarının daha az olduğu; iyimserlik, umut ve iyi oluşlarının daha fazla olduğu söylenebilir. Önceki çalışmalar incelendiğinde; üniversite öğrencilerinin olumsuz durumlar karşısında öz yargılama olmadan kendine özenli olmalarının, olumsuzlukları hayatın bir parçası olarak görmelerinin, mantıklı bir bilinçle farkındalığa sahip olmalarının onların sevinç, mutluluk, coşku, heyecan, gurur, güven gibi olumlu duygularını arttıracağı; kaygı, üzüntü, korku, incinmişlik, kızgınlık gibi olumsuz duygularını azalacağı sonucunu destekler nitelikte olduğu söylenebilir.

Araştırma bulgularına göre, üniversite öğrencilerinin mükemmeliyetçilik özelliklerini öz anlyış negatif yönde anlamlı bir şekilde yordamaktadır. Bu bulguya göre, üniversite öğrencilerinin kendilerini yargılamak yerine kendine karşı sıcak ve anlayışlı olmalarının, yapılan hatalar karşısında kendini izole ederek sadece kendisi yapıyormuş gibi davranmak yerine bu durumu herkesin yaşayabileceği bir durum olarak görmelerinin, olumsuz duygu ve düşünceleri bastırmak yerine olduğu gibi kabul etmelerinin; daha az mükemmeliyetçi eğilimler göstermelerini sağlayacağ1 söylenebilir. Araştırma bulguları, öz anlayışın uyumsuz mükemmeliyetçilikle (Barnett ve Sharp, 2016; Chang, Pua ve Ng, 2019; Ferrari, Yap, Scott, Einstein ve Ciarrochi, 2018; Fletcher, vd., 2019; Fong ve Cai, 2019; Linnett ve Kibowski, 2020; Mehr ve Adams, 2016; Stoeber, Lalova ve Lumley, 2020; Yeshua, Zohar ve Berkovich, 2019), özel eleştirel mükemmeliyetçilikle (Richardson, Trusty ve George, 2020), nörotik mükemmeliyetçilik ve öz eleştiriyle (Neff, 2003b), ailesel eleştiriyle (Potter, Yar, Francis ve Schuster, 2014), kendine, başkalarına ve sosyal düzene yönelik mükemmeliyetçilikle (Hiçdurmaz ve Aydın, 2017) ve yüksek standartlar şemasıyla (Thimm, 2017) negatif yönde ilişkili olduğunu bulan araştırma sonuçlarını desteklemektedir. Otrar ve Bükköse-Tezcan (2015) öz yargılama, soyutlama, aşırı özdeşleşme düzeyleri ile kendine, başkalarına ve sosyal düzene yönelik mükemmeliyetçilik 
arasında pozitif yönlü anlamlı bir ilişki bulmuştur. Linnett ve Kibowski (2018), hata yapma endişesi ve gerçek başarılar ile yüksek beklentiler arasındaki algılanan tutarsızlıkla ifade edilen mükemmeliyetçiliğin olumsuz boyutlarını öz anlayış ile negatif yönde ilişkili bulmuştur. Çalışma bulgularından hareketle yüksek düzeyde öz anlayışın mükemmeliyetçiliğin olumsuz doğasıyla ters yönde ilişkili olduğu söylenebilir. Bu araştırmanın bulguları öz anlayış ve mükemmeliyetçiliğin ilişkisini inceleyen önceki araştırma bulgularını desteklemektedir. Mükemmeliyetçilik; gerçekçi olmayan standartlar belirleme, sorunlara neden olmasına rağmen bu standartlara ulaşmak için aşırı gayret ve öz eleştirel bir tutum sergileme (Shafran vd., 2010) ile karakterize edilebilir. Öz eleştiriyi, gerçekçi olmayan yüksek standartlar belirlemek ve eksiklikler için kendini aşırı yargılayarak suçlamak şeklinde tanımlayacak olursak; öz eleştirinin mükemmeliyetçilikle yakından ilişkili olabileceği söylenebilir (Brown, 2011). Yüksek düzeyde öz anlayışa sahip olan birey problemlerini, zayıflıklarını, eksikliklerini görür ve buna rağmen kendini eleştirmek ve kendisine katı bir tutum sergilemek yerine, şefkat ve merhametle yaklaşır. Böylece öz anlayış, olumsuz yaşam olaylarına karşı tampon görevi görebilir ve işler yolunda gitmediğinde bireyin pozitif duygular geliştirmesini sağlayabilir (Leary vd., 2007). Bu çalışmalardan hareketle mükemmeliyetçiliğin olumsuz doğasına sahip bireylerin öz anlayış düzeylerinin düşük olduğu ve yüksek öz anlayış düzeyinin mükemmeliyetçilik için bir antidot olabileceği söylenebilir. Diğer bir deyişle öz anlayış eksikliği mükemmeliyetçiliğin uyumsuz doğasını besleyebilir ve negatif duyguların gelişmesine neden olabilir. Özetle konu ile ilgili yapılan önceki çalışmaların ve kavramsal çerçevenin; üniversite öğrencilerinin kendilerini yargılamak yerine kendine karşı sıcak ve anlayışlı olmalarının, yapılan hatalar karşısında kendini izole ederek sadece kendisi hata yapıyormuş gibi davranmak yerine bu durumu herkesin yaşayabileceği bir durum olarak görmelerinin, olumsuz duygu ve düşünceleri bastırmak yerine olduğu gibi kabul etmelerinin; mükemmeliyetçi özellikler ile ters yönde ilişki olduğu bulgusunu destekler nitelikte olduğu söylenebilir.

$\mathrm{Bu}$ araştırmada dikkate alınması gereken birtakım sınırlılıklar bulunmaktadır. İlk olarak bu araştırmanın verileri Necmettin Erbakan Üniversitesi Ahmet Keleşoğlu Eğitim Fakültesinin farklı bölümlerinde öğrenim görmekte olan öğrencilerden toplanmıştır. Gelecek araştırmalarda farklı üniversite ve fakültelerde öğrenim görmekte olan öğrenciler ve daha geniş bir çalışma grubu üzerinde bu araştırmanın tekrarlanması önerilmektedir. Öz anlayışı artırmaya yönelik müdahale programları hazırlanarak mükemmeliyetçiliğin ve negatif duyguların azaltılmasına yönelik çalışmalar yapılabilir.

\section{Kaynaklar}

Akyol, Ü. (2011). Ergenlerde iletişim becerilerinin yordayıclları olarak öz-duyarlık ve mizah tarzları. (Yüksek

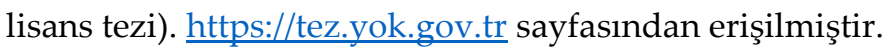


Arslan, C. (2018). Interpersonal problem solving, self-compassion and personality traits in university students. Educational Research and Reviews 11(7), 474-481. doi: 10.5897/ERR2015.2605

Arslan, C., \& Adıgüzel, G. (2018). Investigation of university students' aggresion levels in terms of empathic tendency, self-compassion and emotional expression. European Journal of Education Studies, 5(4), 46-53. doi: 10.5281/zenodo.1461079

Arslan, C., Hamarta, E., Üre, Ö., \& Özyeşil, Z. (2010). An investigation of loneliness and perfectionism in university students. Procedia-Social and Behavioral Sciences, 2(2), 814-818. doi: 10.1016/j.sbspro.2010.03.109

Arslan, C., Oral, T., \& Karababa, A. (2018). Examination of secondary school students' hope levels in terms of anxiety, depression and perfectionism. Education and Science, 43(194), 101-110. doi: 10.15390/EB.2018.6592

Bacanlı, F., \& Çarkıt, E. (2020). Öz şefkatin cinsiyete göre incelenmesi: Meta analiz çalışması. Ege Ĕ̆itim Dergisi, 21(2), 1-15. doi: 10.12984/egeefd.648331

Barnett, M. D., \& Sharp, K. J. (2016). Maladaptive perfectionism, body image satisfaction, and disordered eating behaviors among US college women: The mediating role of selfcompassion. Personality and Individual Differences, 99, 225-234. doi: 10.1016/j.paid.2016.05.004

Baş, Z., \& Dilmaç, B. (2019). Predictive relationship between values, self-compassion and humor styles of adolescents. Research on Education and Psychology (REP), 3(2), 80-90.

Brophy, K., Brähler, E., Hinz, A., Schmidt, S., \& Körner, A. (2020). The role of self-compassion in the relationship between attachment, depression, and quality of life. Journal of Affective Disorders, 260, 45-52. doi: 10.1016/j.jad.2019.08.066

Brown, B. (2011). Mükemmel olmamanın hediyeleri (I. Ölmez, Çev.). İstanbul: Butik Yayıncılık.

Butkovic, A., Brkovic, I., \& Bratko, D. (2012). Predicting well-being from personality in adolescents and older adults. Journal of Happiness Studies, 13(3), 455-467. doi: 10.1007/s10902-011-9273-7

Büyüköztürk, Ş., Kılıç-Çakmak, E., Akgün, Ö. E., Karadeniz, Ş., \& Demirel, F. (2008). Bilimsel araştırma yöntemleri. Ankara: Pegem Akademi.

Castro, J., Soares, M., J., Pereira, A., T., \& Macedo, A. (2017). Perfectionism and negative/positive affecet associations: The role of cognitive emotion regulation and perceived distress/coping. Trends in Psychiatry and Psychotherapy, 39(2), 77-87. doi: 10.1590/2237-6089-2016-0042

Chang, D., Pua, X. C., \& Ng, S. S. L. (2019). Relationship between self-compassion, perfectionism, and body image satisfaction among university students in Malaysia. A Research Project Submitted in Partial Fulfillment of the Requirements for the Bachelor of Social Science (Hons) Psychology, Faculty of Arts and Social Science, Universiti Tunku Abdul Rahman. 
Cohen, J. (1992). A power primer. Psychological Bulletin, 112(1), 155-159. doi: 10.1037//00332909.112.1.155

Curran, T., \& Hill, A. P. (2019). Perfectionism is increasing over time: A meta-analysis of birth cohort differences from 1989 to 2016. Psychological Bulletin, 145(4), 410-429. doi: 10.1037/bul0000138

Çağlar, A., \& Taş, B. (2018). The analysis of the relationship between bereavement degrees of adolescents who have lost their parents and their self-compassion. Research on Education and Psychology (REP), 2(2), 144-155.

Çarkıt, E. (2016). Üniversite öğrencilerinin düşünce hataları ve duygular ifade etmelerinin mükemmeliyetçilik tutumlarını yordaması. (Yüksek lisans tezi). https://tez.yok.gov.tr sayfasından erişilmiştir.

Çarkıt, E., \& Yalçın, S. B. (2018). Üniversite öğrencilerinin düşünce hataları ve duygularını ifade etmelerinin mükemmeliyetçilik tutumlarını yordaması. Sakarya Üniversitesi Eğitim Bilimleri Dergisi, 8(1), 195-210. doi: $10.19126 /$ suje.367429

DeNeve, K. M., \& Cooper, H. (1998). The happy personality: A meta-analysis of 137 personality traits and subjective well-being. Psychological Bulletin, 124, 197-229. doi: 10.1037/0033-2909.124.2.197

Deniz, M. E., Arslan, C., Özyeşil, Z., \& İzmirli, M. (2012). Öz anlayış, yaşam doyumu, pozitif ve negatif duygu: Türk ve diğer ülke üniversite öğrencileri arasında bir karşılaştırma. Mehmet Akif Ersoy Üniversitesi Eğitim Fakültesi Dergisi(23), 428-446.

Deniz, M. E., Kesici Ş., \& Sümer A. S. (2008). The validity and reliability study of the turkish version of Self Compassion Scale. Social Behavior and Personality: An International Journal, 36(9), 1151-1160. doi: $\underline{10.2224 / s b p .2008 .36 .9 .1151}$

Deniz, M. E., \& Sümer, A. S. (2010). Farklı öz-anlayış düzeylerine sahip üniversite öğrencilerinde depresyon, anksiyete ve stresin değerlendirilmesi. Ĕ̆itim ve Bilim, 35(158), 115-127.

Diener, E. (1984). Subjective well-being. Psychological Bulletin, 95, 542-75.

Diener, E., Larsen, R. J., Levine, S., \& Emmons, R. A. (1985). Intensity and frequency: Dimensions underlying positive and negative affect. Jourruil of Personality and Social Psychology, 48, 12531265. doi: $10.1037 / / 0022-3514.48 .5 .1253$

Dilmaç, B., Aydoğan, D., Koruklu, N., \& Deniz, M. E. (2009). İlköğretim öğrencilerinin mükemmeliyetçilik özelliklerinin mantık dışı inançlarla açıklanabilirliği. İlköğretim Online, $8(3), 720-728$.

Dilmaç, B., Deniz, M., \& Deniz, M. E. (2009). Üniversite öğrencilerinin öz-anlayışıları ile değer tercihlerinin incelenmesi. Değerler Ĕ̆itimi Dergisi, 7(18), 9-24. 
Dunkley, D. M., Zuroff, D. C., \& Blankstein, K. R. (2003). Self-critical perfectionism and daily affect: dispositional and situational influences on stress and coping. Journal of Personality and Social Psychology, 84, 234-52. doi: 10.1037/0022-3514.84.1.234

Eker, H. (2011). Üniversite öğrencilerinin öz-duyarlık ve duyarlı sevgi düzeylerinin ebeveyn tutumları açısından tutumları açısından incelenmesi. (Yüksek lisans tezi). https://tez.yok.gov.tr sayfasından erişilmiştir.

Eliüşük-Bülbül, A., \& Arslan, C. (2017). Investigation of patience tendency levels in terms of selfdetermination, self-compassion and personality features. Universal Journal of Educational Research 5(9), 1632-1645. doi: 10.13189/ujer.2017.050921

Ferrari, M., Yap, K., Scott, N., Einstein, D. A., \& Ciarrochi, J. (2018). Self-compassion moderates the perfectionism and depression link in both adolescence and adulthood. PloS One, 13(2), e0192022. https://doi.org/10.1371/journal.pone.0192022

Fletcher, K., Yang, Y., Johnson, S. L., Berk, M., Perich, T., Cotton, S., ..., \& Murray, G. (2019). Buffering against maladaptive perfectionism in bipolar disorder: The role of self-compassion. Journal of Affective Disorders, 250, 132-139. doi: 10.1016/j.jad.2019.03.003

Fong, R. W., \& Cai, Y. (2019). Perfectionism, self-compassion and test-related hope in Chinese primary school students. The Asia-Pacific Education Researcher, 28(4), 293-302.

Frost, R. O., Lahart, C. M., \& Rosenblate, R. (1991). The development of perfectionism: A study of daughters and their parents. Cognitive Therapy and Research, 15(6), 469-489.

Frost, R. O., Marten, P., Lahart, C., \& Rosenblate, R. (1990). The dimensions of perfectionism. Cognitive Therapy and Research, 14, 449-468.

Gençöz, T. (2000). Pozitif ve Negatif Duygu Ölçeği: Geçerlik ve güvenirlik çalışması. Türk Psikoloji Dergisi, 15(46), 19-26.

Gilbert, P., \& Procter, S. (2006). Compassionate mind training for people with high shame and selfcriticism: Overview and pilot study of a group Nyanaponika Therapy approach. Clinical Psychology \& PsychoNyanaponika Therapy, 13(6), 353-379. doi: 10.1002/cpp.507

Hewitt, P. L., \& Flett, G. L. (1991). Perfectionism in the self and social contexts: Conceptualization, assessment, and association with psychopathology. Journal of Personality and Social Psychology, 60, 456-470. doi: $\underline{10.1037 / 0022-3514.60 .3 .456}$

Hiçdurmaz, D., \& Aydın, A. (2017). The relationship between nursing students' self-compassion and multidimensional perfectionism levels and the factors that influence them. Journal of Psychiatric Nursing, 8(2), 86-94.

Hu, L., \& Bentler, P. M. (1998). Fit indices in covariance structure modeling: Sensitivity to 
underparameterized model misspecification. Psychological Methods, 3(4), 424-453. doi: 10.1037/1082-989X.3.4.424

Hu, L. T., \& Bentler, P. M. (1999). Cutoff criteria for fit indexes in covariance structure analysis: Conventional criteria versus new alternatives. Structural Equation Modeling: A Multidisciplinary Journal, 6(1), 1-55. doi: 10.1080/10705519909540118

İme, Y., \& Taş, B. (2018). The investigation of relationships between childhood traumatic events and self-compassion among adolescents. Research on Education and Psychology (REP), 2(2), 136-143.

James, K., Verplanken, B., \& Rimes, K. A. (2015). Self-criticism as a mediator in the relationship between unhealthy perfectionism and distress. Personality and Individual Differences, 79, 123128. doi: $10.1016 /$ j.paid.2015.01.030

Kağan, M. (2011). Psychometric properties of the Turkish version of the Frost Multidimensional Perfectionism Scale. Anadolu Psikiyatri Dergisi, 12(3), 192-197.

Karababa, A. (2018). The relationship between adaptive-maladaptive perfectionism and life satisfaction among secondary school students. Research on Education and Psychology (REP), 2(2), 166-175.

Kaygısız, F., \& Traş, Z. (2019). A review on adolescents' resilience in terms of submissive behaviors and self-compassion. Research on Education and Psychology (REP), 3(2), 127-141.

Kobori, O., \& Tanno, Y. (2005). Self-oriented perfectionism and its relationship to positive and negative affect: The mediation of positive and negative perfectionism cognitions. Cognitive Therapy and Research, 29(5), 555-567. doi: 10.1007/s10608-005-2835-4

Krieger, T., Hermann, H., Zimmermann, J., \& Holtforth, M., G. (2015). Associations of self-compassion and global self-esteem with positive and negative affect and stress reactivity in daily life: Findings from a smart phone study. Personality and Individual Differences, 87, 288-292. doi: 10.1016/j.paid.2015.08.009

Leary, M. R., Tate, E. B., Adams, C. E., Allen, A. B., \& Hancock, J. (2007). Self-compassion and reactions to unpleasant self-relevant events: The implications of treating oneself kindly. Journal of Personality and Social Psychology, 92, 887-904. doi: 10.1037/0022-3514.92.5.887

Levine, S. L., Green-Demers, I., Werner, K. M., \& Milyavskaya, M. (2019). Perfectionism in adolescents: Self-critical perfectionism as a predictor of depressive symptoms across the school year. Journal of Social and Clinical Psychology, 38(1), 70-86. doi: 10.1521/jscp.2019.38.1.70 
Limburg, K., Watson, H. J., Hagger, M. S., \& Egan, S. J. (2017). The relationship between perfectionism and psychopathology: A meta-analysis. Journal of Clinical Psychology, 73(10), 1301-1326. doi: 10.1002/jclp.22435

Linnett, R. J., \& Kibowski, F. (2018, July 5). A closer look at multidimensional perfectionism and multidimensional self-compassion. https://doi.org/10.31234/osf.io/bcu37

Linnett, R. J., \& Kibowski, F. (2020). A multidimensional approach to perfectionism and selfcompassion. Self and Identity, 19(7), 757-783. doi: 10.1080/15298868.2019.1669695

Mehr, K. E., \& Adams, A. C. (2016). Self-compassion as a mediator of maladaptive perfectionism and depressive symptoms in college students. Journal of College Student Psychotherapy, 30(2), 132145. doi: $\underline{10.1080 / 87568225.2016 .1140991}$

Myers, D. G., \& Diener, E. (1995). Who is happy? Psychological Science, 6(1), 10-17. doi: 10.1111/j.14679280.1995.tb00298.x

Neff, K. D. (2003a). Self-compassion: An alternative conceptualization of a healthy attitude toward oneself. Self and Identity, 2(2), 85-101. doi: 10.1080/15298860390129863

Neff, K. D. (2003b). The development and validation of a scale to measure self-compassion. Self and Identity, 2(3), 223-250. doi: $\underline{10.1080 / 15298860390209035}$

Neff, K. D. (2009). The role of self-compassion in development: A healthier way to relate to oneself. Human Development, 52, 211-214. doi: 10.1159/000215071

Neff, K. D. (2012). The science of self-compassion. C. Germer, \& R. Siegel (Eds.), Compassion and Wisdom in Psychotherapy içinde (s. 79-92). New York: Guilford Press.

Neff, K. D. (2016). The Self-Compassion Scale is a valid and theoretically coherent measure of selfcompassion. Mindfulness, 7(1), 264-274. doi: 10.1007/s12671-015-0479-3

Neff, K. D., Hsieh, Y., \& Dejitterat, K. (2005). Self-compassion, achievement goals, and coping with academic failure. Self and Identity, 4(3), 263-287. doi: 10.1080/13576500444000317

Neff, K. D., Kirkpatrick, K. L., \& Rude, S. S. (2006). Self-compassion and adaptive psychological functioning. Journal of Research in Personality, 41, 139-154. doi: 10.1016/i.jrp.2006.03.004

Neff, K. D., \& Lamb, L. M. (2009). Self-compassion. S. Lopez (Ed.), The encyclopedia of positive psychology içinde (s. 864-867). Oxford: Blackwell Publishing.

Neff, K. D., \& McGehee, P. (2010). Self-compassion and psychological resilience among adolescents and young adults. Self and Identity, 9, 222-240. doi: $10.1080 / 15298860902979307$

Neff, K. D., Rude, S. S., \& Kirkpatrick, K. L. (2007). An examination of self-compassion in relation to positive psychological functioning and personality traits. Journal of Research in Personality, 41(4), 908-916. doi: 10.1016/j.jrp.2006.08.002 
Neff, K. D., \& Vonk, R. (2009). Self-compassion versus global self-esteem: Two different ways of relating to oneself. Journal of Personality, 77, 23-50. doi: 10.1111/j.1467-6494.2008.00537.x

Nejad, E. M. H., Besharat, M. A., Haddadi, P., \& Abdolmanafi, A. (2011). Mediation effects of positive and negative affects on the relationship between perfectionism and physical health. Procedia Social and Behavioral Sciences, 30, 176 -181. doi: 10.1016/j.sbspro.2011.10.035

Oral, T., \& Arslan, C. (2017). The investigation of university students' forgiveness levels in terms of self-compassion, rumination and personality traits. Universal Journal of Educational Research, 5(9), 1447-1456. doi: 10.13189/ujer.2017.050902

Otrar, M., \& Bükköse-Tezcan, H. (2015). Rehberlik ve psikolojik danışma öğrencilerinin öz duyarlıkları ile mükemmeliyetçilikleri arasındaki ilişkinin incelenmesi. Ĕ̆itim ve Öğretim Araştırmaları Dergisi, 4(3), 163-172.

Öveç, Ü. (2007). Öz duyarlık ile öz bilinç, depresyon, anksiyete ve stres arasındaki ilişkilerin yapısal eşitlik modeliyle incelenmesi. (Yüksek lisans tezi). https://tez.yok.gov.tr sayfasından erişilmiştir.

Pommier, E., Neff, K. D., \& Tóth-Király, I. (2020). The development and validation of the Compassion Scale. Assessment, 27(1), 21-39. doi: $10.1177 / 1073191119874108$

Potter, R., Yar, K., Francis, A. J., \& Schuster, S. (2014). Self-compassion mediates the relationship between parental criticism and social anxiety. International Journal of Psychology and Psychological Therapy, 14(1), 33-43.

Richardson, C. M., Trusty, W. T., \& George, K. A. (2020). Trainee wellness: self-critical perfectionism, self-compassion, depression, and burnout among doctoral trainees in psychology. Counselling Psychology Quarterly, 33(2), 187-198. doi: $\underline{10.1080 / 09515070.2018 .1509839}$

Shafran, R., Egan, S., \& Wade, T. (2010). Overcoming perfectionism. Londra: Constable and Robinson.

Stoeber, J., Lalova, A. V., \& Lumley, E. J. (2020). Perfectionism, (self-) compassion, and subjective wellbeing: A mediation model. Personality and Individual Differences. doi: 10.1016/j.paid.2019.109708

Sünbül, Z. A., \& Güneri, O. Y. (2019). The relationship between mindfulness and resilience: The mediating role of self compassion and emotion regulation in a sample of underprivileged Turkish adolescents. Personality and Individual Differences, 139, 337-342. doi: 10.1016/j.paid.2018.12.009

Tabachnick, B. G., \& Fidell, L. S. (2013). Using multivariate statistics (6th ed.), Boston: Allyn and Bacon.

Tellegen, A. (1985). Structures of mood and personality and their relevance to assessing anxiety, with an emphasis on self-report. A. H. Tuma \& J. D. Maser (Eds.), Anxiety and the anxiety disorders içinde (s. 681-706). Hillsdale, NJ: Erlbaum. 
Thimm, J. C. (2017). Relationship between early maladaptive schemas, mindfulness, self-compassion, and psychological distress. International Journal of Psychology and Psychological Therapy, 17(1), 317.

Trompetter, H. R., de Kleine, E., \& Bohlmeijer, E. T. (2017). Why does positive mental health buffer against psychopathology? An exploratory study on self-compassion as a resilience mechanism and adaptive emotion regulation strategy. Cognitive Therapy and Research, 41(3), 459-468. doi: $\underline{10.1007 / s 10608-016-9774-0}$

Watson, D., Clark, L. A., \& Tellegen, A. (1984). Cross-cultural convergence in the structure of mood: A Japanese replication and a comparison with U.S. findings. Journal of Personality and Social Psychology, 47, 127-144. doi: $\underline{10.1037 / 0022-3514.47 .1 .127}$

Watson, D., Clark, L. A., \& Tellegen, A. (1988). Development and validation of brief measure of positive and negative affect: The panas scales. Journal of Personality and Social Psychology, 54(6), 1063-1070. doi: 10.1037//0022-3514.54.6.1063

Wu, Q., Chi, P., Zeng, X., Lin, X., \& Du, H. (2019). Roles of anger and rumination in the relationship between self-compassion and forgiveness. Mindfulness, 10(2), 272-278. doi: 10.1007/s12671-018$\underline{0971-7}$

Yang, Y., Zhang, M., \& Kou, Y. (2016). Self-compassion and life satisfaction: The mediating role of hope. Personality and Individual Differences, 98, 91-95. doi: 10.1016/j.paid.2016.03.086

Yeshua, M., Zohar, A. H., \& Berkovich, L. (2019). “Silence! The body is speaking”-a correlational study of personality, perfectionism, and self-compassion as risk and protective factors for psychosomatic symptoms distress. Psychology, Health $\mathcal{E}$ Medicine, 24(2), 229-240. doi: $\underline{10.1080 / 13548506.2018 .1546016}$

\section{Extended Summary}

Perfectionism, which is a multi-dimensional personality trait (Frost, Marten, Lahart, \& Rosenblate, 1990; Hewitt, \& Flett, 1991), is that the individual acquires strict standards, pursues these standards despite causing problems, and evaluates himself with an extremely critical attitude based on his/her performance in this process (Frost, et al., 1990; Frost, Lahart, \& Rosenblate, 1991; Shafran, Egan, \& Wade, 2010). One of the widely investigated multidimensional models of perfectionism is the six-dimensional model of Frost et al. (1990): Anxiety to make mistakes, not being sure about what it is doing, personal standards, high perception of family criticism, high perception of family expectations, and order.

It is thought that self-compassion can be a protective factor in the face of the negative consequences of perfectionism. Individuals who show compassion for themselves do not make harsh 
judgment and self-criticism against them (Neff, 2003a, 2003b; Neff, Hsieh, \& Dejitterat, 2005). The fact that the individual can embrace his own flaws, be loving, compassionate, and kind to himself can act as a buffer against the devastating effects of perfectionism. Because having self-compassion is the tendency of the individual not to over criticize himself/herself for being flawed and faulty (Pommier, Neff, \& Tóth-Király, 2020), and this feature is a feature that is lacking in negative perfectionism (Frost et al., 1990; James, Verplanken, \& Rimes, 2015). Self-compassion is the extension of kindness, care, warmth, and understanding (instead of beratement and criticism) toward oneself when faced with shortcomings, inadequacies, or failures (Neff, 2003a). It can be said that self-compassion is closely related to desired characteristics such as positive affect, subjective well-being, and life satisfaction.

According to the researches, it has been reported that negative perfectionism has become more widespread in recent years (e.g. Curran \& Hill, 2019). Considering the prevalence (Curran \& Hill, 2019) and negative results of perfectionism in young people (Arslan, Oral, \& Karababa, 2018; Castro, Soares, Pereira, \& Macedo, 2017; Limburg, Watson, Hagger, \& Egan, 2017), it is important to know the concepts related to perfectionism in preventing perfectionism and intervening in it. In addition, it is important to know the concepts related to positive and negative affect in order to provide subjective well-being. Therefore, in this study, we aimed to investigate the role of selfcompassion in predicting the positive-negative affect and perfectionism characteristics of university students.

The relational survey method was administered in this study. In this study, the relationships between positive-negative affect, perfectionism, and self-compassion of university students were investigated. Structural Equation Modeling was used to examine the predictive role of selfcompassion.

The study group consisted of 303 students (248 women - 81.8\%; 55 men - 18.2\%) who were randomly selected and enrolled in the Ahmet Keleşoğlu Faculty of Education at Necmettin Erbakan University in 2017-2018 academic year. The mean age of the study group was 20.51 years (Standard Deviation $=2.15)$. In the study, 'Self Compassion Scale', 'Positive-Negative Affect Scale' and 'Frost Multidimensional Perfectionism Scale' were used as data collection tools. SPSS 23 and AMOS 22 software were used in the analysis of the data. The goodness of fit values ( $\chi 2 / \mathrm{sd} \leq 5$; RMSEA $\leq .07$; SRMR $\leq .07 ; \mathrm{NNFI}>.80$ ) for the model tested using the Maximum likelihood statistic were evaluated within the limits (Byrne, 2011).

As a result of the structural equation modeling, it is concluded that self compassion is a significant predictor of positive-negative affect and perfectionism. Self-compassion is a meaningful predictor of perfectionism $(\beta=-.582, \mathrm{p}=0.000)$, positive affect $(\beta=.470, \mathrm{p}=0.000)$, and negative affect $(\beta=-.485, p=0.000)$. Self-compassion explains about $34 \%$ of the total variance of perfectionism 
$(R 2=.339, p=0.000)$, about $22 \%$ of the total variance of positive affect $(R 2=.220, p=0.000)$, and about $24 \%$ of the total variance of negative affect $(R 2=.236, p=0.000)$. That the goodness of fit of the model is $\chi^{2}=1107.124 ; \mathrm{p}=0.000 ; \mathrm{df}=459 ; \chi 2 / \mathrm{df}=2.41 ; \mathrm{RMSEA}=.06 ; \mathrm{SRMR}=.07 ; \mathrm{NNFI}=.82$ indicates acceptable compliance (Byrne, 2011). Self-compassion affects the anxiety of making mistakes $(\mathrm{d}=-.53)$, suspicion of behavior $(\mathrm{d}=-.40)$, familial criticism $(\mathrm{d}=-.32)$, family expectations $(\mathrm{d}=-.28)$ and personal standards $(\mathrm{d}=-.27)$ negatively and indirectly, while positively and indirectly influences order $(\mathrm{d}=.02)$. Self-compassion influences positive affect positively $(\mathrm{d}=.47)$, while negative affect directly influences negative affect $(\mathrm{d}=-.48)$. According to Cohen $(1992), .10 \mathrm{low}, .30$ medium, .50 and above are interpreted as strong in the interpretation of correlation based effect sizes.

The finding that self-compassion is an important predictor of positive-negative affect is similar to previous research results (e.g., Deniz, Arslan, Özyesil, \& Izmirli, 2012; Deniz, Kesici, \& Sumer, 2008; Deniz \& Sumer, 2010; Kriger, Hermann, Zimmermann, \& Holtforth, 2015; Leary, Tate, Adams, Allen, \& Hancock, 2007; Neff, 2003b; Neff, Rude, \& Kirkpatrick, 2007; Neff \& Vonk, 2009; Öveç, 2007; Trompetter, de Kleine, \& Bohlmeijer, 2017; Yang, Zhang, \& Kou, 2016). The finding that selfcompassion is an important predictor of perfectionism is similar to previous research results (e.g., Barnett \& Sharp, 2016; Chang, Pua, \& Ng, 2019; Ferrari, Yap, Scott, Einstein, \& Ciarrochi, 2018; Fletcher et al., 2019; Fong \& Cai, 2019; Linnett \& Kibowski, 2020; Mehr \& Adams, 2016; Stoeber, Lalova, \& Lumley, 2020; Yeshua, Zohar, \& Berkovich, 2019).

There are a number of limitations and recommendations to consider in this research. First of all, the data of this research was obtained from students in different departments of Necmettin Erbakan University, Ahmet Keleşoğlu Education Faculty. In future research, it is recommended to work on students in different universities, faculties, and departments and with a larger working group. The second limitation of this study is that most of the study group was women. For future studies, it is possible to study working groups with a balanced gender distribution. Self-compassionbased intervention programs can be prepared to reduce perfectionism. It is thought that selfcompassion-based case conceptualization might be beneficial for the perfectionist during the counseling process.

\section{Araştırmacıların Katkı Oranı Beyanı}

$\mathrm{Bu}$ araştırma makalesinin hazırlanmasında araştırmacılar eşit oranda katkı sağlamıştır.

\section{Destek ve Teşekkür Beyanı}

Bu araştırmada herhangi bir kurum, kuruluş ya da kişiden destek alınmamıştır. 


\section{Çatışma Beyanı}

Araştırmacının araştırma ile ilgili diğer kişi ve kurumlarla herhangi bir kişisel ve finansal çıkar çatışması yoktur.

\section{Etik Kurul Beyanı}

$\mathrm{Bu}$ araştırma, Nevşehir Hacı Bektaş Veli Üniversitesi Etik Kurulunun 12.03.2020 tarih ve 2020.08.62 sayılı onayı ile yürütülmüştür. 